Article

\title{
Subjective Well-Being in Spanish Adolescents: Psychometric Properties of the Scale of Positive and Negative Experiences
}

\author{
Vicente Prado-Gascó ${ }^{1}\left[\right.$, Virginia Romero-Reignier ${ }^{2}{ }^{\circledR}$, Patricia Mesa-Gresa ${ }^{3}{ }^{\circledR}$ and \\ Ana Belén Górriz ${ }^{4, *}$ \\ 1 Social Psychology Department, Universitat de València, Avda. Blasco Ibáñez 21, 46010 Valencia, Spain; \\ vicente.prado@uv.es \\ 2 Faculty of Social Sciences, European University of Valencia, C/ General Elio, n ${ }^{\circ}$ 8, 46010 Valencia, Spain; \\ virginia.romero@universidadeuropea.es \\ 3 Psychobiology Department, Universitat de València, Avda. Blasco Ibáñez 21, 46010 Valencia, Spain; \\ Patricia.Mesa@uv.es \\ 4 Developmental, Educational, Social and Methodological Psychology Department, Universitat Jaume I, \\ Castellón, Avda. Sos Baynat, s/n, 12071 Castellón, Spain \\ * Correspondence: gorriz@uji.es; Tel.: +34-964-729671
}

Received: 6 March 2020; Accepted: 12 May 2020; Published: 14 May 2020

\begin{abstract}
The scale of positive and negative experiences (SPANE) assesses emotional responses and their frequency of manifestation in recent weeks. This scale has been validated in different countries and populations but not in Spanish adolescents. The aim was to evaluate the psychometric properties of SPANE in two samples: (1) Sample I included 797 adolescents $(\mathrm{M}=15.5$ years old, $\mathrm{SD}=0.68,54.2 \%$ female) and, (2) Sample II included 1433 adolescents ( $\mathrm{M}=13.7$ years old, $\mathrm{SD}=1.27,53.2 \%$ female). Finally, a subsample from sample II was analyzed in different stages (after six and 12 months) with 298 adolescents $(\mathrm{M}=13.7$ years old, $\mathrm{SD}=1.13,58.7 \%$ female). The results obtained have adequate levels of reliability and validity that seem to justify the use of this diagnostic tool in the Spanish adolescent population.
\end{abstract}

Keywords: emotional response; adolescence; validation; psychological assessment

\section{Introduction}

In recent years, interest in well-being and the improvement of quality of life has been increasing; these are now considered important aspects of any stage of life [1]. Several studies have shown their influence on factors such as health, interpersonal relationships, and performance [2]. In particular, different studies have established an association between well-being and an improvement in social relationships [3-5], academic outcomes [6,7], physical and mental health [7-10], resilience and overcoming posttraumatic stress disorder [11-15], academic performance [16-18], satisfaction with school [19-22], and emotional skills, as well as a decrease in somatic complaints [23-25].

The phenomenon of well-being has been considered in research from a wide variety of perspectives. However, there seems to be a certain degree of consensus when considering specific perspectives with respect to well-being: the eudaimonic and hedonic perspectives [26]. Eudaimonic well-being is related to psychological well-being and is defined by variables such as happiness, full functioning, satisfaction, and vitality; while hedonic well-being, focused on subjective well-being, includes emotions and moods related to greater positive affect and life satisfaction, and less negative affect [26]. These two approaches appear to refer to two different aspects of the so-called subjective well-being, the emotional response of 
the subject (positive and negative affect) and the cognitive component (assessment of different aspects related to satisfaction with life) [26-29].

The literature emphasizes that the study of well-being during different stages of life can contribute to the identification and prevention of potential psychosocial risks. In particular, the assessment of well-being at ages such as adolescence can be particularly relevant because this period includes psychological, social, and cognitive changes that make adolescents particularly vulnerable to various risky situations and/or psychological problems [30,31]. For this reason, and due to the scarcity of research in this regard, the study of well-being in childhood and adolescence requires deeper analysis [32-35].

In order to develop research, it is necessary to have reliable and valid instruments. Therefore, the study of the psychometric properties of the instruments is a crucial aspect [36]. Scale development is the process of creating a scale or test. This process can involve different phases, from the establishment of different indicators (items) to the measurement of a construct and the assessment of its suitability via expert judgement, to the analysis of its psychometric properties (reliability and validity) in different populations and samples [37-40]. Based on a review of the literature, a pool of items is created in the first phases. Later, this pool is submitted to expert judgement to determine the suitability, importance, and/or clarity for the measurement of the construct under study. Then, the usual procedure is to create a preliminary version that will be applied to a pilot sample, and the first analysis of its reliability and validity will be carried out. Based on the results obtained, the final scale will be formed [41]. Once a scale has been developed, it needs to be validated, a process that consists of different analytical processes that seek to obtain evidence of the suitability of the instrument in terms of its content, internal structure, relations to other variables, response processes, and consequences that can be predicted [42]. Although a scale or questionnaire may be valid for a particular population, this does not mean that it works equally well for other populations, contexts, and languages [36]. Therefore, if scales are to be administered in different samples (e.g., different age groups or different languages), they must be adapted and validated anew for the new samples according to the international methodological standards for adapting an instrument to a foreign language recommended by different authors and associations, such as the International Test Commission (ITC) [43,44]. Measuring well-being in children and adolescents is very complex, and scales designed for adults have normally been used without previous adaptation or validation for a child population [45,46]. Nonetheless, some instruments have emerged for use in these types of populations, such as the Students' Life Satisfaction Scale (SLSS) [17] and the Multidimensional Students' Life Satisfaction Scale (MSLSS) by Huebner [47], as well as the Comprehensive Quality of Life Scale-School Version by Cummins [48]. However, most of these scales have focused on the cognitive component [49], ignoring the emotional or affective component of well-being, which is one of the most relevant aspects during this stage to ensure good personal and social adjustment, and the study of their psychometric properties has been scarce. To resolve these issues, Watson et al. [50] developed a tool called the Positive and Negative Affect Scale (PANAS) with a version for children and adolescents that is more oriented toward measuring the emotional component [51]. Nevertheless, this scale has been questioned because it includes descriptors that are not feelings and disregards other feelings that should be included. Another important limitation lies in its complexity and the difficulty of its use in a transcultural way [52].

To overcome these limitations, Diener et al. [53] proposed the Scale of Positive and Negative Experience (SPANE). This questionnaire, together with the Satisfaction with Life Scale (SWLS) and the Flourishing Scale, addresses the assumption that well-being is a multidimensional concept [54], including hedonic and eudaimonic approaches to well-being. The SWLS and the Flourishing Scale intend to measure the psychological functioning as well as the cognitive dimension of subjects and is supported by the eudaimonic approach, whereas the SPANE measures feelings and is based on the hedonic approach [54]. As the authors of the scale point out, the SPANE intends to assess "subjective feelings of well-being and ill-being" [53]. Among the advantages of SPANE is the use of general feelings, which include a large number of emotions and feelings such as joy, affect, and happiness (positive feelings) and sadness, fear, and anger (negative feelings) [53]. Moreover, previous research has demonstrated that, 
to assess subjective well-being, it is more appropriate to use the frequency of experiences rather than the intensity, which is what was usually done with other instruments [55]. More specifically, SPANE assesses the frequency with which the subject has experienced these feelings in the last four weeks. This fact is also an advantage when comparing it to other scales because it permits the collection of information that is more precise and less affected by the effects of forgetting [56]. Another advantage of the scale is that it allows for the assessment of general positive and negative feelings from a simple way, which makes it easier to understand in different cultures and contexts, encouraging its use in diverse societies.

Regarding the psychometric properties of SPANE, the original version [53] showed good validity and reliability, and validations were carried out in the following countries: Portugal [54], Japan [56], China [57], Turkey [58], Germany [59], Italy [60], Peru [61], and Serbia [62]. The adequate internal consistency of the scale in the validation carried out by Diener et al. [53] was found with Cronbach's alphas of 0.81 to 0.89 . Validation was carried out with students and full-time workers and indicated a high correlation between the scores of the positive (SPANE-P) and negative (SPANE-N) items $(\mathrm{r}=-0.60)$. A principal axis factor analysis indicated that SPANE-P and SPANE-N supported one strong factor in both subscales, with an eigenvalue above one, factor loadings from 0.49 to 0.81 and variance of $61 \%$ and $53 \%$, respectively. Test-retest reliabilities over a month ranged from 0.62 to 0.68 ; however, the stability has not been tested for one year after its implementation in any research yet. Moreover, there were significant correlations between SPANE-P and SPANE-N with diverse measures. Specifically, SPANE-P showed positive correlations with measures of satisfaction with life, happiness, optimism, and positive emotions and a negative correlation with measures of negative emotions and loneliness. SPANE-N showed the opposite correlations [53].

Although the psychometric properties of SPANE have been previously analyzed in different samples, this validation has not been realized with a Spanish sample and very few studies have been carried out in adolescents. A previous study performed by Jovanović et al. [62], using a sample composed of Serbian young adults and adolescents, was carried out to analyze the incremental validity of SPANE on predicting well-being, satisfaction, and depression over the PANAS. This study did not include an analysis of reliability, validity, internal consistency, or other psychometric properties. Furthermore, only one study has adapted the scale to a Spanish-speaking sample, specifically from Latin America, and analyzed its properties [61]. However, this adaptation has been carried out with a relatively small sample of university students and has not analyzed the validity of the instrument in depth through confirmatory factor analyses or discriminant and/or convergent analysis. The study also failed to analyze the composite reliability and time stability of the instrument. In the specific case of Spain, there are no studies on the adaptation and validation of the SPANE; the scale has been translated by León-Pinilla et al. [63], but its psychometric properties have not been evaluated yet. In view of these circumstances, the main aim of the present study was to evaluate the psychometric properties of SPANE in a large sample of Spanish adolescents, with more than 2200 participants aged between 12 and 18 years. Taking into account previous research, the validation of SPANE with a sample of adolescents has been scarcely studied in the existing literature, and no previous study has evaluated the psychometric properties of this scale in a Spanish sample. This validation has been realized in terms of item analysis, internal consistence reliability, internal validity, convergent and discriminant validity, and score stability. The statistical analyses performed, as suggested by experts [44] and based on the validations of this scale made in other countries [54,56-62], included descriptive statistics (mean scores, standard deviation, the item-total correlations, Cronbach alphas if the items were deleted) for each item, a Cronbach alpha test, the composite reliability coefficient (CRC) and average variance extracted (AVE), the Kaiser-Meyer-Olkin test (KMO), Bartlett's test of sphericity, and confirmatory factor analysis (CFA). The validity of SPANE was examined through the exploration of the correlations with other measures related to mood, satisfaction of life, or somatic complaints using Pearson's correlation between the Somatic Complaint List (SCL), the Mood Questionnaire (MOOD), the Satisfaction with Life Scale (SWLS), and SPANE. The stability of the scores was also analyzed through a paired $t$-test and Pearson's 
correlations by comparing the results after six and 12 months and a temporal invariance analysis. Centile scores have also been calculated to facilitate the interpretation of the data and the diagnosis of adolescents. Hence, the main purpose is to provide an instrument that is reliable and easy to apply to the Spanish adolescent population to assess their well-being.

\section{Materials and Methods}

\subsection{Participants}

To attain the objectives set out for the present study, with the aim of analyzing the stability of psychometric indicators as well as generalization through cross-validity with independence of the sample used [64,65], two samples from four distinct moments in time were used. First, as recommended by the ITC [55], a pilot sample (sample I) was used to evaluate the language forms to ensure a proper understanding of the scale and to obtain evidence for reliability and validity. The psychometric properties of the scale were then analyzed in a large sample of adolescents (sample II). Finally, to test the stability of the psychometric properties of the scale over time, a subsample was extracted from sample II. By conducting a convenience sampling of participation that controlled for sex and age, $50 \%$ of the subjects included in the study were encouraged to participate. Despite this issue, only 298 subjects completed more than 90\% of the questionnaire in Stages 2 and 3, because some subjects changed schools or repeated grades. In general, there do not seem to be any differences between the adolescents who participated in the different stages. Sample I was composed of 797 adolescents, sample II included 1433 adolescents, and a subsample of 298 adolescents extracted from sample II was taken at six- and 12-month intervals. All the adolescents were selected by a convenience sampling method and were drawn from a range of working to upper-middle-class areas.

- Sample I. This sample included 797 adolescents aged 14 to $18(\mathrm{M}=15.5$ years old, $\mathrm{SD}=0.68$; $54.2 \%$ female). They were selected from 42 high schools in the Valencia region (64\%), Palma de Mallorca (19\%), and Murcia (17\%) (Spain).

- Sample II (Stage 1). Sample II was composed of 1433 adolescents aged 11 to 18 (M=13.7 years old; $\mathrm{SD}=1.27 ; 53.2 \%$ female) who were attending high school in the Valencia region (Spain).

- Sample II (Stages 2 and 3). A total of 298 adolescents were selected from sample II. The participants aged 12 to 18 ( $\mathrm{M}=13.7$ years old, $S D=1.13 ; 58.7 \%$ female). For this sample, the same instruments implemented with sample II were used to collect data six months (Stage 2) and one year later (Stage 3).

\subsection{Instruments}

\subsubsection{The Scale of Positive and Negative Experiences (SPANE)}

This scale was developed by Diener et al. [53] and translated into Spanish by León-Pinilla et al. [63]. This scale assesses positive and negative feelings. It is a brief 12-item scale with six items devoted to positive experiences (SPANE-P) and six items designed to assess negative experiences (SPANE-N) felt in the past four weeks. Each SPANE item is scored on a scale ranging from 1 to 5, where 1 represents "very rarely or never" and 5 represents "very often or always." The two scores can be combined by subtracting the negative score from the positive score, obtaining the hedonic balance score (SPANE-B).

\subsubsection{The Mood Questionnaire (MOOD)}

The Mood Questionnaire (MOOD) [66] has beenadapted for Spanish children [67]. This questionnaire included 16 items grouped in four mood scales: Happiness, Anger, Sadness, and Fear. The participants were instructed to answer each item on a three-point response scale ( $1=$ never, $2=$ sometimes, $3=$ often). In all dimensions, higher scores indicate a greater presence of that mood state. In earlier studies [68] as well as the validation of the Spanish context [67], the scales displayed adequate psychometric properties. In the present study, they are also adequate: Sadness $\alpha=0.77$; Fear $\alpha=0.65$; Anger $\alpha=0.78$; Happiness $\alpha=0.84$. 


\subsubsection{The Somatic Complaint List (SCL)}

The Somatic Complaint List (SCL) [69,70] has been validated by Górriz et al. [24]. This list consists of 11 items and identifies the frequency with which children experienced and felt pain in the past four weeks, such as stomachaches, headaches, and so on. It has a three-point response scale: for example, "I never/sometimes/often feel dizzy" or "I never/sometimes/often have pain in my chest." Again, a higher score indicates a greater presence of somatic complaints. The scale was adapted for adult and university samples $[53,54,56,58]$ and for adolescent samples [24]. Previous studies have shown this list to be very reliable and valid, $\alpha=0.78$ [24]. This was also the case in the present study ( $\alpha=0.81$ ).

\subsubsection{The Satisfaction with Life Scale (SWLS)}

This scale [71], that was adapted in the Spanish context [72], measures the cognitive evaluation or judgment of one's overall life and consists of five items. Each item is answered on a seven-point Likert-type scale ranging from $1=$ strongly disagree to $7=$ strongly agree. It includes items such as "I am satisfied with my life" and "In most ways, my life is close to my ideal." The items are summed up to form a general score of satisfaction with life. Previous studies [71] have shown this scale to have adequate psychometric properties $(\alpha=0.87)$, which was also the case in this study $(\alpha=0.88)$.

\subsection{Procedure}

The abovementioned questionnaires were administered collectively during regular class time in one session lasting approximately $30 \mathrm{~min}$. SPANE was administered to Sample I and II (Stages 1,2 , and 3), while the SCL, MOOD, and SWLS questionnaires were administered to Sample II (Stages 1, 2, and 3). The necessary consent from the local government, schools, parents, and ethical university commission (Ethics Commission in Experimental Research of the University of Valencia, Code H1385330676977) was obtained before recruiting the children, and written informed consent was obtained. The effect of the question order in the questionnaires was controlled. The SPANE was adapted according to the international methodological standards recommended by the International Test Commission (ITC) for adapting an instrument to a foreign language [44].

\subsection{Analysis}

The statistical analysis was conducted using SPSS (Statistical Package for the Social Sciences, Version 22, Armonk, NY, USA: IBM Corp.) as well as EQS (Structural Equation Modeling Software, Version 6.2, Temple City, CA, USA: Multivariate Software, Inc.). First, the descriptive statistics (mean scores, standard deviation, the item-total correlations, Cronbach alphas if the items were deleted) for each item were calculated, which was followed by an analysis of the empirical evidence for the reliability and validity of the scale on each sample. For the reliability analysis, the Cronbach alpha test, composite reliability coefficient (CRC) and average variance extracted (AVE) were calculated. Regarding the validity analysis, first, the adequacy of the data using the Kaiser-Meyer-Olkin test (KMO) and Bartlett's test of sphericity was tested. Second, a confirmatory factor analysis (CFA) in the different samples were conducted. Third, convergent and discriminant validity was tested, and finally, criterial validity was studied through an analysis of the link between the SCL, MOOD SWLS and SPANE using Pearson's correlations.

Subsequently, the stability of the scores was analyzed by means of a paired $t$-test of samples from Stage 1 and Stage 2 and from Stage 1 and Stage 3, a Pearson's correlation of SPANE dimensions in the three different moments of sampling, and factorial invariance of the instrument considering different stages. Finally, the centiles of the scores according to sex and age were calculated. 


\section{Results}

\subsection{Analyses of Items and Reliability}

The 12 items from the SPANE scale were analyzed from sample I as well as sample II (Stages 1, 2, and 3) used in the study. Table 1 presents the item mean scores, standard deviation, the item-total correlations, the Cronbach alphas, and alphas if the items were deleted.

The results show that the set of items contributes adequately to the scale and that the scale does not improve by eliminating any of the items if the Cronbach alphas of sample I are considered $(\alpha=0.84$, $0.79<\alpha<0.83)$ as well as in the diverse stages of sample II assessed $(\alpha=0.81,0.80<\alpha<0.82$ in Stage $1 ; \alpha=0.87,0.80<\alpha<0.82$ in Stage 2; $\alpha=0.89,0.78<\alpha<0.84$ in Stage 3). Additionally, the two dimensions show an adequate composite reliability coefficient (CRC) and average variance extracted (AVE) $[73,74]$ (sample I: CRC $=0.86$ and AVE $=0.54$ in positive feelings; $\mathrm{CRC}=0.81$ and $\mathrm{AVE}=0.47$ in negative feelings; in sample II-Stage $1: \mathrm{CRC}=0.93$ and AVE $=0.63$ in positive feelings; $\mathrm{CRC}=0.90$ and AVE $=0.58$ in negative feelings; in subsample II-Stage 2: CRC $=0.95$ and AVE $=0.66$ in positive feelings; $\mathrm{CRC}=0.88$ and $\mathrm{AVE}=0.56$ in negative feelings, and in subsample II-Stage 3: CRC $=0.91$ and $\mathrm{AVE}=0.62$ in positive feelings; $\mathrm{CRC}=0.86$ and $\mathrm{AVE}=0.53$ in negative feelings). These results are similar to those found in the original scale (SPANE-P $\alpha=0.87$; SPANE-N $\alpha=0.81$ ) $[53,54]$.

\subsection{Validity Analysis}

Second, we proceeded to study the internal validity of the scale. For this, we first observed the adequacy of the data using the Kaiser-Meyer-Olkin test (KMO) (0.89 for sample I and 0.91 for Stage 1 of sample I, 0.92 for Stage 2, and 0.90 for Stage 3 of subsample II) and Bartlett's test of sphericity $(p<0.001$ in all samples and stages).

We proceeded to carry out three confirmatory factor analyses (CFA) with the maximum likelihood estimation (ML) using the Satorra-Bentler robust correction $[75,76]$ to control the possibility of non-normal distributions of the data (Table 2) in each of the study samples and stages. In all cases, as suggested by the literature [53], all the items that composed the instrument were grouped into two correlated factors. It has not been considered necessary to include information concerning the single-factor model since there seems to be sufficient evidence on the two-dimensional structure of the instrument.

Based on the significance of the $\chi^{2}$ statistic $(<0.01)$, an adequate model fit cannot be ensured in any of the cases. However, given that this statistic is very susceptible to sample size, other goodness-of-fit indices were applied, such as the ratio between $\chi^{2}$ and its degrees of freedom (df) as well as the Satorra-Bentler scale $\chi^{2}\left(\mathrm{~S}-\mathrm{B} \chi^{2}\right)$ and its degrees of freedom, where values under 5 were adequate; the Comparative Fit Index (CFI), the Incremental and the McDonald's Fit Indices (IFI and MFI, respectively), where values above 0.90 are indicators of a good result [75,76]; and the Root Mean Square Error of Approximation (RMSEA), where the adequate fit scores are equal to or below 0.08 . Table 2 presents a summary of these indicators for each CFA.

The obtained results appear to justify the internal validity of the instrument in the different stages and samples. Following this, to increase empirical evidence for construct validity, the convergent and discriminant validity of the scale was calculated based on the results obtained in the CFA [77]. To this end, the adoption of the Fornell-Larcker criterion [78] has been widely accepted by many authors [79-85]. This criterion postulates that the convergent validity of the measurement model can be assessed using the Average Variance Extracted (AVE) and Composite Reliability (CR), whereas the discriminant validity can be assessed by comparing the amount of the variance captured by the construct (AVE) and the shared variance with other constructs. 
Table 1. Item analysis: Mean (M), standard deviation (SD), item-total correlation (rjx), Cronbach's alpha if the item was deleted ( $\alpha$-x), Cronbach's alpha ( $\alpha$ ), Composite Reliability Coefficient (CRC) and average variance extracted (AVE) of the SPANE in the four samples.

\begin{tabular}{|c|c|c|c|c|c|c|c|c|c|c|c|c|c|c|c|c|}
\hline \multirow{3}{*}{ Items } & \multicolumn{4}{|c|}{$\begin{array}{c}\text { Sample I } \\
(n=797 ; \alpha=0.84)\end{array}$} & \multicolumn{4}{|c|}{$\begin{array}{l}\text { Sample II-Stage } 1 \\
(n=1433 ; \alpha=0.87)\end{array}$} & \multicolumn{4}{|c|}{$\begin{array}{c}\text { Sample II-Stage } 2 \\
(n=298 ; \alpha=0.92)\end{array}$} & \multicolumn{4}{|c|}{$\begin{array}{c}\text { Sample II-Stage } 3 \\
(n=298 ; \alpha=0.89)\end{array}$} \\
\hline & \multicolumn{4}{|c|}{$(0.79<\alpha<.083)$} & \multicolumn{4}{|c|}{$(0.80<\alpha<0.82)$} & \multicolumn{4}{|c|}{$(0.78<\alpha<0.84)$} & \multicolumn{4}{|c|}{$(0.78<\alpha<0.84)$} \\
\hline & $\mathbf{M}$ & SD & rjx & $\alpha .-x$ & $\mathbf{M}$ & SD & rjx & $\alpha .-x$ & $\mathbf{M}$ & SD & rjx & $\alpha .-x$ & $\mathbf{M}$ & SD & rjx & $\alpha .-x$ \\
\hline Positive experiences (SPANE-P) & \multicolumn{4}{|c|}{$\alpha=0.84 ; \mathrm{CRC}=0.85 ; \mathrm{AVE}=0.49$} & \multicolumn{4}{|c|}{$\alpha=0.88 ; \mathrm{CRC}=0.93 ; \mathrm{AVE}=0.63$} & \multicolumn{4}{|c|}{$\alpha=0.92 ; \mathrm{CRC}=0.94 ; \mathrm{AVE}=0.66$} & \multicolumn{4}{|c|}{$\alpha=0.90 ; \mathrm{CRC}=0.94 ; \mathrm{AVE}=0.66$} \\
\hline $1-\ldots$ positive & 3.76 & 0.9 & 0.71 & 0.81 & 3.75 & 0.96 & 0.7 & 0.86 & 4.04 & 0.87 & 0.64 & 0.92 & 3.81 & 0.85 & 0.68 & 0.89 \\
\hline $3-\ldots$ good & 3.91 & 0.85 & 0.7 & 0.82 & 3.8 & 0.94 & 0.73 & 0.86 & 4.03 & 0.96 & 0.85 & 0.89 & 3.88 & 0.89 & 0.75 & 0.88 \\
\hline $5-\ldots$ pleasant & 3.88 & 0.90 & 0.63 & 0.83 & 3.83 & 0.99 & 0.72 & 0.86 & 3.99 & 0.97 & 0.83 & 0.89 & 3.85 & 0.94 & 0.81 & 0.87 \\
\hline 7-... happy & 4 & 0.95 & 0.64 & 0.83 & 3.94 & 1.03 & 0.74 & 0.85 & 4.04 & 1.04 & 0.75 & 0.90 & 3.98 & 0.91 & 0.78 & 0.88 \\
\hline $10-\ldots$ joyful & 3.97 & 0.95 & 0.65 & 0.82 & 3.88 & 1.05 & 0.73 & 0.86 & 3.92 & 1.10 & 0.81 & 0.9 & 3.92 & 1 & 0.77 & 0.88 \\
\hline $12-\ldots$ of satisfaction & 3.6 & 1.09 & 0.52 & 0.85 & 3.5 & 1.14 & 0.55 & 0.89 & 3.64 & 1.15 & 0.73 & 0.91 & 3.58 & 1.1 & 0.63 & 0.9 \\
\hline Negative experiences (SPANE-N) & \multicolumn{4}{|c|}{$\alpha=0.79 ; \mathrm{CRC}=0.80 ; \mathrm{AVE}=0.43$} & \multicolumn{4}{|c|}{$\alpha=0.82 ; \mathrm{CRC}=0.90 ; \mathrm{AVE}=0.58$} & \multicolumn{4}{|c|}{$\alpha=0.87 ; \mathrm{CRC}=0.94 ; \mathrm{AVE}=0.71$} & \multicolumn{4}{|c|}{$\alpha=0.85 ; \mathrm{CRC}=0.93 ; \mathrm{AVE}=0.66$} \\
\hline $2-\ldots$ negative \# & 3.23 & 1 & 0.7 & 0.73 & 2.42 & 1.02 & 0.67 & 0.77 & 2.57 & 1.02 & 0.75 & 0.84 & 2.6 & 0.96 & 0.72 & 0.81 \\
\hline $4-\ldots$ bad \# & 3.52 & 1.03 & 0.69 & 0.73 & 2.29 & 1.06 & 0.7 & 0.76 & 2.4 & 1.09 & 0.82 & 0.82 & 2.37 & 1.04 & 0.78 & 0.8 \\
\hline $6-\ldots$ unpleasant & 3.68 & 1.04 & 0.63 & 0.74 & 2.07 & 1.06 & 0.63 & 0.78 & 2.23 & 1.16 & 0.76 & 0.83 & 2.25 & 1.06 & 0.67 & 0.82 \\
\hline $8-\ldots$ of sadness \# & 3.49 & 1.12 & 0.63 & 0.74 & 2.28 & 1.08 & 0.64 & 0.77 & 2.37 & 1.12 & 0.73 & 0.84 & 2.39 & 1.02 & 0.72 & 0.81 \\
\hline $9-\ldots$ of fear \# & 4.2 & 1.05 & 0.31 & 0.82 & 1.7 & 1.02 & 0.34 & 0.84 & 1.81 & 1.06 & 0.36 & 0.9 & 1.84 & 1.02 & 0.4 & 0.87 \\
\hline $11-\ldots$ of anger \# & 3.42 & 1.05 & 0.39 & 0.8 & 2.46 & 1.05 & 0.51 & 0.80 & 2.54 & 1.1 & 0.62 & 0.86 & 2.64 & 1.05 & 0.57 & 0.84 \\
\hline
\end{tabular}

Note: \# inverted item for global Scale. Acceptable CRC $\geq 0.70$. Acceptable AVE $\geq 0.40$. Abbreviations: AVE: average variance extracted test. 
Table 2. Goodness-of-fit indices of the SPANE questionnaire.

\begin{tabular}{ccccccc}
\hline Model & $\chi^{2}(\mathbf{d f})$ & S-B $\chi^{2}(\mathbf{d f})$ & CFI & IFI & MFI & RMSEA \\
\hline $\begin{array}{c}\text { Sample I } \\
(n=797)\end{array}$ & $145.11(53)$ & $107.96(53)$ & 0.97 & 0.98 & 0.98 & $\begin{array}{c}0.04 \\
(\mathbf{9 5} \% \mathbf{C I})\end{array}$ \\
$\begin{array}{c}\text { Sample II-Stage 1 } \\
(n=1433)\end{array}$ & $149.2(53)$ & $110.9(53)$ & 0.99 & 0.99 & 0.98 & $\left.\begin{array}{c}0.03 \\
(0.022-0.037) \\
0.04\end{array}\right)$ \\
$\begin{array}{c}\text { Subsample II—Stage 2 } \\
(n=298)\end{array}$ & $132.94(53)$ & $77.39(53)$ & 0.98 & 0.98 & 0.96 & $\begin{array}{c}(0.018-0.060) \\
0.02\end{array}$ \\
$\begin{array}{c}\text { Subsample II-Stage 3 } \\
(n=298)\end{array}$ & $97.7(53)$ & $60.13(53)$ & 0.99 & 0.99 & 0.99 & \begin{tabular}{c}
$0.000-0.046)$ \\
\hline
\end{tabular}
\end{tabular}

Note: Bartlett's test of sphericity ( $p<0.001$ in all samples and stages); Ratio Chi-square $\left(\chi^{2}\right)$ and degrees of freedom (df); Ratio Satorra-Bentler Scaled Chi-square (S-B $\chi^{2}$ ) and df: adequate $\leq 5$; Comparative Fit Index (CFI), Incremental Fit Index (IFI), McDonald's Fit Index (MFI): adequate $\geq 0.90$; Root Mean Square Error of Approximation (RMSEA): adequate $\leq 0.08$; Confidence interval $(\mathrm{CI})$.

In terms of the convergent validity, it seems that all the items that make up the SPANE questionnaire were significantly and strongly correlated with the latent variable that they were assumed to measure, with $t$ values above 3.291 in all cases [39,77]. In addition, discriminant validity was evaluated through the average variance extracted test (AVE) [86] (Table 3). To determine the existence of discriminant validity, the AVE square root must be higher than the correlation among the pairs of factors or dimensions considered [85].

Table 3. Correlations of the SPANE dimensions among time in sample II.

\begin{tabular}{cccc}
\hline Samples \& Stages & Dimensions & 1. SPANE-P & 2. SPANE-N \\
\hline Sample I & 1. SPANE-P & $(0.69)$ & \\
(Stage 0) & 2. SPANE-N & $-0.31^{* *}$ & $(0.66)$ \\
Sample II & 1. SPANE-P & $(0.76)$ & \\
(Stage 1) & 2. SPANE-N & $-0.36^{* *}$ & $(0.68)$ \\
Subsample II & 1. SPANE-P & $(0.79)$ & \\
(Stage 1) & 2. SPANE-N & $-0.30^{* *}$ & $(0.76)$ \\
Subsample II & 1. SPANE-P & $(0.81)$ & \\
(Stage 1) & 2. SPANE-N & $-0.28^{* *}$ & $(0.84)$ \\
Subsample II & 1. SPANE-P & $(0.81)$ & \\
(Stage 1) & 2. SPANE-N & $-0.41^{* *}$ & $(0.81)$ \\
\hline
\end{tabular}

Note: ${ }^{* *} p<0.01$. AVE Square root on the diagonal. Abbreviations: SPANE: Scale of Positive and Negative Experiences; P: positive; N: negative.

The results displayed in Table 3 suggest acceptable convergent and discriminant validity in all samples and stages.

Subsequently, the relationships between the constructs were examined to determine the criterion/nomological validity of this instrument (Table 4) [1,3,24]. Therefore, Pearson's correlation coefficients were calculated for the SPANE, the SWLS, and the SCL and MOOD scales in sample II, Stages 1, 2, and 3 .

Based on the results obtained (Table 4) it can be seen that the SWLS scale correlates in a positive, moderate and significant way $(p \leq 0.01)$ with SPANE-P $(r=0.47)$ and the hedonic balance $(r=0.49)$ and in a negative, moderate and significant way $(p \leq 0.01)$ with SPANE-N $(r=-0.34)$. These results were in line with the expected, since, according to the characteristics of the SWLS scale described by Diener et al. [71], to measure subjective well-being it is necessary to take into consideration both the affective component (measured by SPANE) and the cognitive component (measured by SWLS). In the same way, a positive, moderate and significant correlation was found $(p \leq 0.01)$ in the SCL with negative feelings $(r=0.42)$ and a negative, moderate, significant correlation was found $(p \leq 0.01)$ in the SCL with positive feelings $(r=-0.37)$ and the hedonic balance $(r=-0.48)$. Finally, with respect to 
the MOOD scale, a negative, moderate, and significant correlation $(p \leq 0.01)$ was observed with the SPANE scale between the hedonic balance and the negative mood states-sadness $(r=-0.55)$, fear $(\mathrm{r}=-0.36)$ and anger $(\mathrm{r}=-0.33)$-and a positive, moderate, and significant correlation with the positive mood state of happiness $(\mathrm{r}=0.48)$.

Table 4. Correlations of the SPANE questionnaire with other variables in Sample II.

\begin{tabular}{|c|c|c|c|c|c|c|c|c|c|c|}
\hline \multirow{2}{*}{ Scales } & \multirow{2}{*}{ Dimensions } & \multicolumn{3}{|c|}{ SPANE } & \multirow{2}{*}{$\begin{array}{c}\text { SWLS } \\
4\end{array}$} & \multirow{2}{*}{$\frac{\mathrm{SCL}}{5}$} & \multicolumn{4}{|c|}{ MOOD } \\
\hline & & 1 & 2 & 3 & & & 6 & 7 & 8 & 9 \\
\hline \multirow{3}{*}{ SPANE } & 1. SPANE-P & 1 & & & & & & & & \\
\hline & 2. SPANE-N & $-0.36^{* *}$ & 1 & & & & & & & \\
\hline & 3. SPANE-B & $0.84^{* *}$ & $-0.81^{* *}$ & 1 & & & & & & \\
\hline SWLS & 4. SWLS & $0.47^{* *}$ & $-0.34^{* *}$ & $0.49 * *$ & 1 & & & & & \\
\hline SCL & 5. SCL & $-0.37^{* *}$ & $0.42^{* *}$ & $-0.48^{* *}$ & $-0.39^{* *}$ & 1 & & & & \\
\hline \multirow{4}{*}{ MOOD } & 6. Sadness & $-0.4^{* *}$ & $0.5^{* *}$ & $-0.55^{* *}$ & $-0.45^{* *}$ & $0.51^{* *}$ & 1 & & & \\
\hline & 7. Fear & $-0.2 * *$ & $0.4^{* *}$ & $-0.36^{* *}$ & $-0.21^{* *}$ & $0.44^{* *}$ & $0.46^{* *}$ & 1 & & \\
\hline & 8. Anger & $-0.2^{* *}$ & $0.36^{* *}$ & $-0.33^{* *}$ & $-0.2^{* *}$ & $0.27^{* *}$ & $0.42 * *$ & $0.26^{* *}$ & 1 & \\
\hline & 9. Happiness & $0.5^{* *}$ & $-0.29^{* *}$ & $0.48^{* *}$ & $0.38^{* *}$ & $-0.3^{* *}$ & $-0.51 * *$ & $-0.18^{* *}$ & $-0.38^{* *}$ & 1 \\
\hline
\end{tabular}

Note: ${ }^{* *} p<0.01$. Abbreviations: MOOD: Mood Questionnaire; SCL: Somatic Complaint List; SPANE: Scale of Positive and Negative Experiences; SWLS: Satisfaction with Life; P: positive; N: negative; B: hedonic balance.

\subsection{Score Stability}

Subsequently, the stability of the scoring obtained was analyzed using three differential methods. First, paired t-tests comparing data obtained in Stage 1 with data after six months (Stage 2) and 12 months (Stage 3) were carried out, followed by an analysis of Pearson's correlation among SPANE factors considering the different sample moments. Finally, the factorial invariance of the instrument was tested.

Based on the results obtained, there does not appear to be any significant differences after six months or after one year when considering positive feelings (Stages 1-2: $t=-1.35, \mathrm{df}=286$, $p=0.178$, Cohen's d $=-0.08, \mathrm{r}=-0.04$; Stages 1-3: $t=-0.65, \mathrm{df}=277, p=0.517$, Cohen's $\mathrm{d}=-0.04$, $\mathrm{r}=-0.02$ ) or the hedonic balance (Stages 1-2: $t=1.28, \mathrm{df}=286, p=0.201$, Cohen's $\mathrm{d}=0.08, \mathrm{r}=0.04$; Stages 1-3: $t=2.17, \mathrm{df}=277, p=0.061$, Cohen's $\mathrm{d}=0.14, \mathrm{r}=0.07$ ). However, there appears to be significant differences in negative feelings with high values after six and 12 months (Stages 1-2: $t=-3.65, \mathrm{df}=286, p=0.000$, Cohen's $\mathrm{d}=-0.23, \mathrm{r}=-0.12$; Stages 1-3: $t=-4.34, \mathrm{df}=277, p=0.000$, Cohen's $\mathrm{d}=-0.27, \mathrm{r}=-0.14)$. Table 3 also presents the correlation between the different factors of the SPANE scale, the four different moments and the two samples. Based on the results obtained, a positive, moderate, and significant correlation appears between the different sample moments in all the dimensions of the SPANE scale. Then, factorial invariance was tested. As suggested by the literature, the measurement invariance test involves the comparison of models in which constraints for matrices to be equal across groups are added $[87,88]$. To analyze the factorial invariance, the two-step process by Jaccard and Wan [89] was used. This process involves first calculating three CFA models. The second step is to calculate two multigroup models using SEM (Stage 1 vs. Stage 2, Stage 1 vs. Stage 3) adding as restriction equal factor variances and another two adding as restriction equal loadings [90]. Changes in the model fit with the inclusion of constraints were tested using a significance test on the difference between the Satorra-Bentler-scaled chi square statistics using SBDIFF [76,91]. The results of the S-B Scaled Difference allow us to assume temporal invariance after 12 months (Satorra-Bentler Scaled Difference $=9.10, \mathrm{df}=10$, Chi Square probability $=0.52$ ) but not after six months (Satorra-Bentler Scaled Difference $=26.44, \mathrm{df}=10$, Chi Square probability $=0.003$ ). All this appears to suggest certain stability in the scoring obtained.

Finally, to facilitate the interpretation of the data obtained from the SPANE scale, centiles were calculated based on the scores of the entire sample and according to gender and age. To that end, the $10,20,30,40,50,60,70,80$, and 90 centiles were calculated (Table 5). 
Table 5. Centile according to sex and age.

\begin{tabular}{|c|c|c|c|c|c|c|c|c|c|c|c|c|c|c|c|c|c|c|}
\hline \multirow{3}{*}{ Centils } & \multicolumn{6}{|c|}{ 12-13 Years Old } & \multicolumn{6}{|c|}{ 14-15 Years Old } & \multicolumn{6}{|c|}{ 16-18 Years Old } \\
\hline & \multicolumn{3}{|c|}{ Men } & \multicolumn{3}{|c|}{ Women } & \multicolumn{3}{|c|}{ Men } & \multicolumn{3}{|c|}{ Women } & \multicolumn{3}{|c|}{ Men } & \multicolumn{3}{|c|}{ Women } \\
\hline & $\mathbf{P}$ & $\mathbf{N}$ & HB & $\mathbf{P}$ & $\mathbf{N}$ & HB & $\mathbf{P}$ & $\mathbf{N}$ & HB & $\mathbf{P}$ & $\mathbf{N}$ & HB & $\mathbf{P}$ & $\mathbf{N}$ & HB & $\mathbf{P}$ & $\mathbf{N}$ & HB \\
\hline 10 & 17 & 6 & 1 & 16 & 7 & 0 & 16 & 6 & 0 & 14 & 9 & -3.1 & 14 & 6 & -2 & 15.4 & 8 & -0.6 \\
\hline 20 & 20 & 7 & 5 & 18 & 8.6 & 3 & 18 & 8 & 4 & 17 & 11 & 0 & 17 & 8 & 0 & 18 & 10.8 & 1 \\
\hline 30 & 22 & 9 & 8 & 20 & 10 & 6 & 20 & 9 & 7 & 18 & 12 & 3 & 18 & 10 & 5 & 19.2 & 12.2 & 3 \\
\hline 40 & 23 & 10 & 10 & 22 & 12 & 8 & 21 & 11 & 8.2 & 20 & 13 & 5 & 21 & 12 & 6 & 21 & 14 & 5.6 \\
\hline 50 & 24 & 12 & 12 & 23 & 13 & 10 & 23 & 12 & 10 & 21 & 14 & 6.5 & 23 & 12 & 9 & 23 & 15 & 9 \\
\hline 60 & 25 & 13 & 14 & 24 & 14 & 12 & 24 & 14 & 12 & 23 & 16 & 9 & 24 & 14 & 11 & 24 & 15 & 9 \\
\hline 70 & 26 & 14 & 16 & 26 & 16 & 14 & 25 & 14 & 14 & 24 & 16 & 11 & 25 & 16 & 13 & 24.8 & 16 & 11 \\
\hline 80 & 28 & 16 & 19 & 28 & 17 & 17 & 26 & 16 & 16 & 26 & 18 & 14 & 28 & 18 & 18 & 26 & 17 & 13.2 \\
\hline 90 & 29 & 18 & 21 & 29 & 18 & 20 & 29 & 18 & 20 & 28 & 19 & 17 & 29 & 21 & 23 & 28.6 & 18 & 17.2 \\
\hline
\end{tabular}

\section{Discussion}

The main aim of the present study was to evaluate the psychometric properties of the SPANE, designed by Diener et al. [53] using adolescents from Spain. This scale has been validated in different contexts and countries, but few studies have used samples composed of adolescents. Although it has been translated into Spanish [61,63] and validated in the Latin American context [61], its psychometric properties have never been tested in Spain. Regarding the results obtained, the analysis of the SPANE items carried out has shown that all contribute adequately to the scale as a whole, as has been observed in previous studies [53,54].

The internal consistency obtained by Cronbach's alpha for the overall scale (SPANE-B $\alpha=0.85$ ) and the factor SPANE-P $(\alpha=0.88)$ and SPANE-N $(\alpha=0.82)$ was adequate. These findings support the original validation (SPANE-P $\alpha=0.87$; SPANE-N $\alpha=0.81$; SPANE-B $\alpha=0.89$ ) [53], as well as the other validations carried out: Portugal (SPANE-P $\alpha=0.90$; SPANE-N $\alpha=0.84$; SPANE-B $\alpha=0.88$ ) [54], Japan (SPANE-P $\alpha=0.91$; SPANE-N $\alpha=0.90$; SPANE-B $\alpha=0.88$ ) [56], China (SPANE-P $\alpha=0.92$; SPANE-N $\alpha=0.91$; SPANE-B $\alpha=0.92$ ) [57], Turkey (SPANE-P $\alpha=0.88$; SPANE-N $\alpha=0.83$ ) [58], Germany (SPANE-P $\alpha=0.88$; SPANE-N $\alpha=0.82$ ) [59], and Italy (SPANE-P $\alpha=0.88$; SPANE-N $\alpha=0.85$; SPANE-B $\alpha=0.92)$ [60].

Furthermore, a confirmatory factor analysis (CFA) was undertaken, which showed sound internal validity of the scale in the different samples. In addition, we proceeded to calculate the convergent and discriminant validity that reinforces these data. The CFA supported the expected two-factor structure that assesses positive and negative feelings and is in line with the original version, the hypothesis of Diener et al. [53], and other validations carried out in different contexts [56,61].

As the literature has shown to date, it seems probable that well-being in adolescents is related to the mood state (MOOD Scale), somatic complaints (SCL Scale), and satisfaction with life (SWLS Scale) $[24,46,54]$. The results from the present study reiterate the findings of the literature because positive feelings and the hedonic balance are related in a positive way to satisfaction and negatively to somatic complaints. Additionally, negative feelings are negatively correlated to satisfaction with life and positively to somatic complaints. Regarding the mood state scale (MOOD), it is important to highlight that it is positively related to the happiness dimension of the scale and negatively to the SPANE scale, the hedonic balance, and the dimensions of sadness, fear, and anger. Previous data have indicated similar correlations between SPANE subscales, confirming our results. Specifically, positive feeling measures by SPANE have shown positive correlations with optimism [56,58], subjective happiness and well-being [59], the positive PANAS subscale [56,59,60], and future expectancies [60]; and negative correlations with pessimism [56], the negative PANAS subscale [56,59,60], and emotional measures such as anxiety, depression, or perceived psychological stress [56,60]. Along the same lines, different studies have indicated a positive correlation between negative feelings measured by SPANE-N and pessimism, anxiety, depression and perceived psychological stress [56,60], negative 
future expectations [60], and the negative PANAS subscale [56,59,60]. Negative correlations between SPANE-N and satisfaction, happiness, optimism, and positive expectations have also been obtained in previous research $[56,60]$.

Furthermore, the stability of the scoring has been analyzed using a variety of methods. Based on the results of the paired $t$-tests and correlations, there seems to be a certain stability in the scoring obtained. Nevertheless, regarding the invariance test, the results on the S-B Scaled Difference allow us to assume temporal invariance after 12 months but not after six months. The lack of stability of the data at six months is probably due to the time at which the data were collected, which was June and July, a period in which adolescents are subjected to greater pressure and stress due to the final evaluation of the course, while the data at Stages 1 and 3 were taken in September and October, after a return from vacation. All this could explain the differences observed at six months but not the differences one year later. Despite this, considering the different methodologies used and according to the results obtained, it seems that stability exists between the different scores obtained in the present study. Finally, the calculations made to obtain the centiles are presented to facilitate the interpretation of the data in future research and the diagnosis of adolescent well-being.

All the data collected appear to confirm that SPANE is an instrument with adequate validity and reliability in a sample of Spanish adolescents, as has been seen in the original validation and in other countries. Some studies have been carried out with university students $[54,56,58]$, while only one was conducted with adolescents [62]. For this reason, the present study is of great importance because it is the first to collect data from a sample of more than 2000 Spanish adolescents aged 12 to 18 years. The main advantages of the use of SPANE are related to the following aspects: First, this scale is easy to administer and quick to complete [60], which makes it especially interesting when it is intended for use with certain populations such as children or adolescents. Second, the fact that the scale includes general and specific items for each subscale (such as "positive" or "negative") means that it can be used in different cultures and contexts, as demonstrated by different previous validations. Moreover, these general concepts include the opportunity to measure all feelings, not only specific ones, with general items and without the need to include extensive lists of items [53,60]. Correlations shown between the subscales of SPANE and other questionnaires indicate that these measures flow properly. Third, the scale is based on the feelings experienced in the last four weeks, so it allows us to assess the recent emotional state of the subject, while maintaining a good balance between emotional state and memory. Finally, as suggested by Diener et al. [53], SPANE allows for the measurement of feelings based on the frequency of their appearance in the last month and not on the intensity. When these types of scales are used in adolescents or young people, these advantages could be very interesting when attempting to obtain an adequate evaluation of the real feelings of the subjects.

Our research has some limitations that should be addressed in future studies. The sample of the study, despite being large, is mainly composed of adolescents from the region of Valencia (Spain). This must be considered in the generalization of the results so it could be interesting, in future validations of SPANE, to expand the sample to adolescents from other regions as well as use subjects from other age groups. Similarly, the evaluation of the psychometric properties of the scale may be relevant in clinical populations. Correlations carried out in previous studies indicated a relationship between measures obtained in positive and negative subscales in SPANE and data from questionnaires, such as the Beck Depression Inventory-II (BDI-II) and the Spielberger State-Trait Anxiety Inventory (STAI-Y) [60]. The validation of SPANE using other clinical questionnaires as well as other measures of well-being such as happiness, flourishing, expectations, and psychological stress could be interesting with a more heterogeneous sample. Finally, we have to consider that our sample was composed of adolescents and the measures obtained were self-reported. As Diener et al. [53] indicated, it might be interesting to complement these measures with others obtained from family, friends, and/or teachers to enrich the results found. 


\section{Conclusions}

In conclusion, the results obtained in our research indicated that the psychometric properties of SPANE are adequate for the Spanish context. These results could be interesting for the advance of the study of well-being and happiness in Spanish adolescents with clinical and research applications. Among the main applications of this validation would be the possibility of having a suitable tool for measuring subjective well-being in the Spanish context, promoting the use of this questionnaire. The fact that SPANE has been validated in other countries allows for a comparison of results between different cultures and contexts. Furthermore, this study has allowed us to analyze the temporal stability of SPANE and to examine in depth the changes in the different levels of well-being of the subjects, which is especially interesting in this field of study. These advances have implications in the field of research, since the results obtained in the present study allow us to advance and consolidate the research on the subjective welfare. Similarly, from a psychological and professional point of view, the main applications contribute to the improvement of the design of more effective prevention and intervention programs, ultimately contributing to the improvement of subjective well-being in adolescents and their environments.

Author Contributions: Conceptualization, V.P.-G. and A.B.G.; methodology, V.P.-G. and A.B.G.; validation, V.P.-G., V.R.-R., P.M.-G., and A.B.G.; formal analysis, V.P.-G.; investigation, V.R.-R. and P.M.-G.; resources, V.R.-R.; data curation, V.R.-R. and P.M.-G.; writing - original draft preparation, V.P.-G., V.R.-R., P.M.-G., and A.B.G.; writing - review and editing, V.P.-G., V.R.-R., P.M.-G., and A.B.G.; visualization, V.P.-G. and A.B.G.; supervision, V.P.-G. and A.B.G. All authors have read and agreed to the published version of the manuscript.

Funding: This research received no external funding.

Conflicts of Interest: The authors declare no conflict of interest.

\section{References}

1. Bojanowska, A.; Zalewska, A.M. Temperamental predictors of subjective well-being from early adolescence to mid-life: The role of temporal and energetic regulation. Int. J. Psychol. 2018, 53, 458-467. [CrossRef]

2. Yahyagil, M.Y. Values, feelings, job satisfaction and well-being: The Turkish case. Manag. Decis. 2015, 53, 2268-2286. [CrossRef]

3. Diener, E.; Seligman, M.E. Very happy people. Psychol. Sci. 2002, 13, 81-84. [CrossRef] [PubMed]

4. Holder, M.D.; Coleman, B.; Sehn, Z.L. The contribution of active and passive leisure to children's well-being. J. Health Psychol. 2009, 14, 378-386. [CrossRef] [PubMed]

5. Lyubomirsky, S.; King, L.; Diener, E. The benefits of frequent positive affect: Does happiness lead to success? Psychol. Bull. 2005, 131, 803-855. [CrossRef] [PubMed]

6. Gilman, R.; Dooley, J.; Florell, D. Relative levels of hope and their relationship with academic and psychological indicators among adolescents. J. Soc. Clin. Psychol. 2006, 25, 166-178. [CrossRef]

7. Marques, S.C.; Pais-Ribeiro, J.; Lopez, S.J. The role of positive psychology constructs in predicting mental health and academic achievement in children and adolescents: A two-year longitudinal study. J. Happiness Stud. 2011, 12, 1049-1062. [CrossRef]

8. Cohen, S.; Alper, C.M.; Doyle, W.J.; Treanor, J.J.; Turner, R.B. Positive emotional style predicts resistance to illness after experimental exposure to rhinovirus or influenza a virus. Psychosom. Med. 2006, 68, 809-815. [CrossRef]

9. Park, N. The role of subjective well-being in positive youth development. Ann. Am. Acad. Political Soc. Sci. 2004, 591, 25-39. [CrossRef]

10. Veenhoven, R. Healthy happiness: Effects of happiness on physical health and the consequences for preventive health care. J. Happiness Stud. 2008, 9, 449-469. [CrossRef]

11. Cohn, M.A.; Fredrickson, B.L.; Brown, S.L.; Mikels, J.A.; Conway, A.M. Happiness unpacked: Positive emotions increase life satisfaction by building resilience. Emotion 2009, 9, 361-368. [CrossRef] [PubMed]

12. Joseph, S.; Linley, P.A.; Joseph, S.; Linley, P. Positive psychological perspectives on posttraumatic stress: An integrative psychosocial framework. In Trauma, Recovery, and Growth: Positive Psychological Perspectives on Posttraumatic Stress; Joseph, S., Linley, P.A., Eds.; John Wiley \& Sons: Hoboken, NJ, USA, 2012; pp. 1-20. 
13. Pargament, K.I.; Desai, K.M.; McConnell, K.M.; Calhoun, L.; Tedeschi, R. Spirituality: A pathway to posttraumatic growth or decline. In Handbook of Posttraumatic Growth: Research and Practice; Calhoun, L.G., Tedeschi, R.G., Eds.; Psychology Press: New York, NY, USA, 2006; pp. 121-137.

14. Tugade, M.M.; Fredrickson, B.L. Resilient individuals use positive emotions to bounce back from negative emotional experiences. J. Pers. Soc. Psychol. 2004, 86, 320-333. [CrossRef] [PubMed]

15. Tugade, M.M.; Fredrickson, B.L. Regulation of positive emotions: Emotion regulation strategies that promote resilience. J. Happiness Stud. 2007, 8, 311-333. [CrossRef]

16. Cheng, H.; Furnham, A. Personality, peer relations, and self-confidence as predictors of happiness and loneliness. J. Adolesc. 2002, 25, 327-339. [CrossRef]

17. Huebner, E.S. Correlates of life satisfaction in children. Sch. Psychol. Q. 1991, 6, 103-111. [CrossRef]

18. Huebner, E.S.; Alderman, G.L. Convergent and discriminant validation of a children's life satisfaction scale: Its relationship to self-and teacher-reported psychological problems and school functioning. Soc. Indic. Res. 1993, 30, 71-82. [CrossRef]

19. Baker, J.A. Teacher-student interaction in urban at-risk classrooms: Differential behavior, relationship quality, and student satisfaction with school. Elem. Sch. J. 1999, 100, 57-70. [CrossRef]

20. Casas, F.; Balatescu, S.; Bertran, I.; González, M.; Hatos, A. School satisfaction among adolescents: Testing different indicators for its measurement and its relationship with overall life satisfaction and subjective well-being in Romania and Spain. Soc. Indic. Res. 2013, 111, 665-681. [CrossRef]

21. Huebner, E.S.; Gilman, R. Toward a focus on positive psychology in school psychology. Sch. Psychol. Q. 2003, 18, 99-102. [CrossRef]

22. Raižienė, S.; Garckija, R. Gender differences in subjective well-being and feeling of safety at school: Evidence from cross-lagged relations in a 1-year longitudinal sample. Soc. Darb. Soc. Work 2013, 12, 151-162.

23. Extremera, N.; Salguero, J.M.; Fernandez-Berrocal, P. Trait Meta-Mood and Subjective Happiness: A 7-week Prospective Study. J. Happiness Stud. 2011, 12, 509-517. [CrossRef]

24. Górriz, A.B.; Prado-Gascó, V.J.; Villanueva, L.; González Barrón, R. Psychometric properties of the somatic complaints scale in spanish children and adults. Psicothema 2015, 27, 269-276. [CrossRef]

25. Koydemir, S.; Simsek, O.F.; Schuetz, A.; Tipandjan, A. Differences in How Trait Emotional Intelligence Predicts Life Satisfaction: The Role of Affect Balance Versus Social Support in India and Germany. J. Happiness Stud. 2013, 14, 51-66. [CrossRef]

26. Ryan, R.M.; Deci, E.L. On happiness and human potentials: A review of research on hedonic and eudaimonic well-being. Annu. Rev. Psychol. 2001, 52, 141-166. [CrossRef] [PubMed]

27. Diener, E. Subjective well-being: Three decades of progress American Psychological Association. Psychol. Bull. 1999, 125, 276-302. [CrossRef]

28. Cummins, R.; Eckersley, R.; Pallant, J.; Van Vugt, J.; Misajon, R. Developing a national index of subjective wellbeing: The Australian unity wellbeing index. Soc. Indic. Res. 2003, 64, 159-190. [CrossRef]

29. Diener, E. Assessing subjective well-being: Progress and opportunities. Soc. Indic. Res. 1994, 31, $103-157$. [CrossRef]

30. Smetana, J.G.; Campione-Barr, N.; Metzger, A. Adolescent development in interpersonal and societal contexts. Annu. Rev. Psychol. 2006, 57, 255-284. [CrossRef]

31. Ronen, T.; Hamama, L.; Rosenbaum, M.; Mishely-Yarlap, A. Subjective well-being in adolescence: The role of self-control, social support, age, gender, and familial crisis. J. Happiness Stud. 2014, 17, 81-104. [CrossRef]

32. Casas, F.; Sarriera, J.C.; Abs, D.; Coenders, G.; Alfaro, J.; Saforcada, E.; Tonon, G. Subjective indicators of personal well-being among adolescents. Performance and results for different scales in latin-language speaking countries: A contribution to the international debate. Child Indic. Res. 2012, 5, 28. [CrossRef]

33. Huebner, E.S. Research on assessment of life satisfaction of children and adolescents. Soc. Indic. Res. 2004, 66, 3-33. [CrossRef]

34. Lau, A.; Cummins, R.; McPherson, W. An investigation into the cross-cultural equivalence of the personal wellbeing index. Soc. Indic. Res. 2005, 72, 403-430. [CrossRef]

35. Tiliouine, H.; Cummins, R.; Davern, M. Measuring wellbeing in developing countries: The case of Algeria. Soc. Indic. Res. 2006, 75, 1-30. [CrossRef] 
36. Gunnell, K.E.; Schellenberg, B.J.; Wilson, P.M.; Crocker, P.R.; Mack, D.E.; Zumbo, B.D. A review of validity evidence presented in the journal of sport and exercise psychology (2002-2012): Misconceptions and recommendations for validation research. In Validity and Validation in Social, Behavioral, and Health Sciences; Zumbo, B., Chan, E., Eds.; Springer: Cham, Switzerland, 2014; Volume 54, pp. 137-156. [CrossRef]

37. Hinkin, T.R. A Review of Scale Development Practices in the Study of Organizations. J. Manag. 1995, 21, 967-988. [CrossRef]

38. Hinkin, T.R.; Tracey, J.B.; Enz, C.A. Scale Construction: Developing Reliable and Valid Measurement Instruments. J. Hosp. Tour. Res. 1997, 21, 100-120. [CrossRef]

39. Prado-Gascó, V.; Amara, N.; Olmos-Peñuela, J. Measuring knowledge spillovers transfer from scholars in business schools: Validation of a multiple-item scale. J. Knowl. Manag. 2020. [CrossRef]

40. Robins, R.W.; Hendin, H.M.; Trzesniewski, K.H. Measuring Global Self-Esteem: Construct Validation of a Single-Item Measure and the Rosenberg Self-Esteem Scale. Pers. Soc. Psychol. Bull. 2001, 27, 151-161. [CrossRef]

41. Prado-Gascó, V. Cómo evaluar en psicología: Las emociones. In Recursos Para Educar en Emociones. De la Teoría a la Acción; González Barrón, M.R., Villanueva Badenes, L., Eds.; Ediciones Pirámide: Madrid, Spain, 2014; pp. 57-86.

42. American Educational Research Association; American Psychological Association; National Council on Measurement in Education; Joint Committee on Standards for Educational, \& Psychological Testing (U.S.). Standards for Educational and Psychological Testing; American Educational Research Association: Washington, DC, USA, 2014.

43. Hambleton, R.K.; Lee, M.K. Methods for Translating and Adapting Tests to Increase Cross-Language. In The Oxford Handbook of Child Psychological Assessment; Saklofske, D.H., Reynolds, C.R., Schwean, V.L., Eds.; Oxford University Press: New York, NY, USA, 2013; pp. 172-181.

44. Muñiz, J.; Elosua, P.; Hambleton, R.K. International Test Commission. International Test Commission Guidelines for test translation and adaptation. Psicothema 2013, 25, 151-157. [CrossRef]

45. Casas, F. Subjective social indicators and child and adolescent well-being. Child Indic. Res. 2011, 4, 555-575. [CrossRef]

46. Gilman, R.; Huebner, S. A review of life satisfaction research with children and adolescents. Sch. Psychol. Q. 2003, 18, 192-205. [CrossRef]

47. Huebner, E.S. Preliminary development and validation of a multidimensional life satisfaction scale for children. Psychol. Assess. 1994, 6, 149-158. [CrossRef]

48. Cummins, R. Comprehensive Quality of Life Scale Adult: Manual, 5th ed.; Deakin University: Burwood, Australia, 1997.

49. Paramo, M.A.; Leo, M.K.; Cortés, M.J.; Martin, G. Influence of psychological well-being and vulnerability to addictive behaviors in adolescents from 15 to 18 years old. Rev. Argent. Clínica Psicológica 2015, 24, 167-178.

50. Watson, D.; Clark, L.A.; Tellegen, A. Development and validation of brief measures of positive and negative affect: The PANAS scales. J. Pers. Soc. Psychol. 1988, 54, 1063-1070. [CrossRef] [PubMed]

51. Laurent, J.; Catanzaro, S.J.; E Joiner, T.; Rudolph, K.D.; Potter, K.I.; Lambert, S.; Osborne, L.; Gathright, T. A measure of positive and negative affect for children: Scale development and preliminary validation. Psychol. Assess. 1999, 11, 326-338. [CrossRef]

52. Diener, E.; Wirtz, D.; Biswas-Diener, R.; Tov, W.; Kim-Prieto, C.; Choi, D.W.; Oishi, S. New measures of well-being. In Assessing Well-Being; Diener, E., Ed.; Social Indicators Research Series; Springer: Dordrecht, The Netherlands, 2009; Volume 39.

53. Diener, E.; Wirtz, D.; Tov, W.; Kim-Prieto, C.; Choi, D.-W.; Oishi, S.; Biswas-Diener, R. New well-being measures: Short scales to assess flourishing and positive and negative feelings. Soc. Indic. Res. 2010, 97, 143-156. [CrossRef]

54. Silva, A.J.; Caetano, A. Validation of the flourishing scale and scale of positive and negative experience in Portugal. Soc. Indic. Res. 2013, 110, 469-478. [CrossRef]

55. Diener, E.; Sandvik, E.; Pavot, W.; Gallagher, D. Response artifacts in the measurement of subjective well-being. Soc. Indic. Res. 1991, 24, 35-56. [CrossRef]

56. Sumi, K. Reliability and validity of Japanese versions of the flourishing scale and the scale of positive and negative experience. Soc. Indic. Res. 2014, 118, 601-615. [CrossRef]

57. Li, F.; Bai, X.; Wang, Y. The scale of positive and negative experience (SPANE): Psychometric properties and normative data in a large chinese sample. PLoS ONE 2013, 8. [CrossRef] 
58. Telef, B.B. The positive and negative experience scale adaptation for turkish university students. Eur. Sci. J. 2015, 11, 49-59.

59. Rahm, T.; Heise, E.; Schuldt, M. Measuring the frequency of emotions: Validation of the scale of positive and negative experience (SPANE) in Germany. PLoS ONE 2017, 12. [CrossRef]

60. Corno, G.; Molinari, G.; Baños, R.M. Assessing positive and negative experiences: Validation of a new measure of well-being in an Italian population. Riv. Psichiatr. 2016, 51, 110-115. [CrossRef] [PubMed]

61. Cassaretto Bardales, M.; Martínez Uribe, P. Validación de las escalas de bienestar, de florecimiento y afectividad. Pensam. Psicológico 2017, 15, 19-31.

62. Jovanović, V. Beyond the PANAS: Incremental validity of the Scale of Positive and Negative Experience (SPANE) in relation to well-being. Pers. Individ. Differ. 2015, 86, 487-491. [CrossRef]

63. León-Pinilla, R. La Interpretación en el Contexto de Refugiados: Camino Hacia el Bienestar. Ph.D. Dissertation, University of Jaume I, Castellon de la Plana, Spain, 2015. Available online: https://www.educacion.gob.es/ teseo/mostrarSeleccion.do (accessed on 14 May 2020).

64. Satorra, A. Asymptotic robustness in multiple group linear-latent variable models. Econ. Theory 2002, 18, 297-312. [CrossRef]

65. Kozak, A.; Kozak, R.A. Does Cross-Validation Provide Additional Information in the Evaluation of Regression Models? Can. J. For. Res. 2003, 33, 976-987. [CrossRef]

66. Rieffe, C.; Terwogt, M.; Bosch, J. Emotion understanding in children with frequent somatic complaints. Eur. J. Dev. Psychol. 2004, 1, 31-47. [CrossRef]

67. Górriz, A.B.; Prado-Gascó, V.J.; Villanueva, L.; Ordóñez López, A.; González Barrón, R. The MOOD questionnaire: Adaptation and validation of the spanish version. Psicothema 2013, 25, 252-257. [CrossRef]

68. Rieffe, C.; Villanueva, L.; Adrián, J.; Górriz, A. Quejas somáticas, estados de ánimo y conciencia emocional en adolescentes. Psicothema 2009, 21, 459-464.

69. Rieffe, C.; Oosterveld, P.; Terwogt, M. An alexithymia questionnaire for children: Factorial and concurrent validation results. Pers. Individ. Differ. 2006, 40, 123-133. [CrossRef]

70. Rieffe, C.; Terwogt, M.; Petrides, K.; Cowan, R.; Miers, A.C.; Tolland, A. Psychometric properties of the emotion awareness questionnaire for children. Pers. Individ. Differ. 2007, 43, 95-105. [CrossRef]

71. Diener, E.; Emmons, R.; Larsen, R.; Griffin, S. The Satisfaction with Life Scale. J. Pers. Assess. 1985, 49, 71-75. [CrossRef] [PubMed]

72. Atienza, F.L.; Pons, D.; Balaguer, I.; García-Merita, M. Propiedades psicométricas de la Escala de Satisfacción con la Vida en adolescentes. Psicothema 2000, 12, 314-319.

73. Lloret-Segura, S.; Ferreres-Traver, A.; Hernández-Baeza, A.; Tomás-Marco, I. El análisis factorial exploratorio de los ítems: Una guía práctica, revisada y actualizada. Ann. Psychol. 2014, 30, 1151-1169. [CrossRef]

74. Harman, H.H. Análisis Factorial Moderno; Saltés: Madrid, Spain, 1980.

75. Bentler, P.M. EQS Structural Equations Program Manual; Multivariate software: Encino, CA, USA, 1995.

76. Satorra, A.; Bentler, P.M. A scaled difference chi-square test statistic for moment structure analysis. Psychometrika 2001, 66, 507-514. [CrossRef]

77. Jöreskog, K.G. A general approach to confirmatory maximum likelihood factor analysis. Psychometrika 1969, 34, 183-202. [CrossRef]

78. Fornell, C.; Larcker, D. Evaluating Structural Equation Models with Unobservable Variables and Measurement Error. J. Mark. Res. 1981, 18, 39-50. [CrossRef]

79. Antunes, A.C.; Caetano, A.; Pina, E.; Cunha, M. Reliability and Construct Validity of the Portuguese Version of the Psychological Capital Questionnaire. Psychol. Rep. 2017, 120, 520-536. [CrossRef]

80. Etchezahar, E.; Prado-Gascó, V.; Jaume, L.; Brussino, S. Validación argentina de la Escala de Orientación a la Dominancia Social. Rev. Latinoam. Psicol. 2014, 46, 35-43. [CrossRef]

81. Lai, S.L.; Pham, H.-H.; Nguyen, H.-K.T.; Nguyen, T.-C.; Le, A.-V. Toward Sustainable Overseas Mobility of Vietnamese Students: Understanding Determinants of Attitudinal and Behavioral Loyalty in Students of Higher Education. Sustainability 2019, 11, 383. [CrossRef]

82. Muhammed, A.; Shariff-Ghazali, S.; Said, S.M.; Hassan, M.; Lee, K. Psychometric Properties of a Theory of Planned Behavior Questionnaire for Assessing the Midwives' Intention to Provide Planned Home Birth Services in Nigeria. J. Community Health Nurs. 2020, 37, 77-88. [CrossRef] [PubMed] 
83. Prado-Gasco, V.J.; Quintanilla, I.; Calabuig, F.; Vveinhardt, J. Knowledge management in R\&D teams at a Spanish technical university: Measurement and relations with organizational culture. Eng. Econ. 2015, 26, 398-408. [CrossRef]

84. Schumaher, M.L.N.; Milani, D.; Alexandre, N.M.C. Psychometric properties evaluation of the Psychological Empowerment Instrument in a Brazilian context. J. Nurs. Manag. 2019, 27, 404-413. [CrossRef] [PubMed]

85. Vila, N.; Küster, I.; Aldás, J.; Aldás, J. Desarrollo y validación de escalas de medida en marketing. In Quaderns de Treball; University of Valencia: València, Spain, 2000; Volume 104.

86. Netemeyer, R.; Johnston, M.; Burton, S. Analysis of role conflict and role ambiguity in a structural equations framework. J. Appl. Psychol. 1990, 75, 148-157. [CrossRef]

87. French, B.F.; Holmes Finch, W. Confirmatory Factor Analytic Procedures for the Determination of Measurement Invariance. Struct. Equ. Model. 2006, 13, 378-402. [CrossRef]

88. Widaman, K.F.; Ferrer, E.; Conger, R.D. Factorial Invariance Within Longitudinal Structural Equation Models: Measuring the Same Construct Across Time. Child Dev. Perspect. 2010, 4, 10-18. [CrossRef]

89. Jaccard, J.; Wan, C.K. LISREL Approaches to Interaction Effects in Multiple Regression. Quantitative Applications in the Social Sciences Series (No. 114); Sage Publications: Thousand Oaks, CA, USA, 1996.

90. Singh, J. Measurement issues in cross-national research. J. Int. Bus. Stud. 1995, 26, 597-619. [CrossRef]

91. Crawford, J.R.; Henry, J.D. The Depression Anxiety Stress Scales: Normative data and latent structure in a large non-clinical sample. Brit. J. Clin. Psychol. 2003, 42, 111-131. [CrossRef]

(C) 2020 by the authors. Licensee MDPI, Basel, Switzerland. This article is an open access article distributed under the terms and conditions of the Creative Commons Attribution (CC BY) license (http://creativecommons.org/licenses/by/4.0/). 